\title{
All-optical ultra-high-speed OFDM to Nyquist-WDM conversion
}

Guan, Pengyu; Røge, Kasper Meldgaard; Mulvad, Hans Christian Hansen; Galili, Michael; Hu, Hao; Morioka, Toshio; Oxenløwe, Leif Katsuo

Published in:

Proceedings of the Optical Fiber Communications Conference and Exhibition 2015

Publication date:

2015

Document Version

Peer reviewed version

Link back to DTU Orbit

Citation (APA):

Guan, P., Røge, K. M., Mulvad, H. C. H., Galili, M., Hu, H., Morioka, T., \& Oxenløwe, L. K. (2015). All-optical ultra-high-speed OFDM to Nyquist-WDM conversion. In Proceedings of the Optical Fiber Communications Conference and Exhibition 2015 (pp. 1-3). IEEE.

\section{General rights}

Copyright and moral rights for the publications made accessible in the public portal are retained by the authors and/or other copyright owners and it is a condition of accessing publications that users recognise and abide by the legal requirements associated with these rights.

- Users may download and print one copy of any publication from the public portal for the purpose of private study or research.

- You may not further distribute the material or use it for any profit-making activity or commercial gain

- You may freely distribute the URL identifying the publication in the public portal

If you believe that this document breaches copyright please contact us providing details, and we will remove access to the work immediately and investigate your claim 


\title{
All-Optical Ultra-High-Speed OFDM to Nyquist-WDM Conversion
}

\author{
P. Guan, K. M. Røge, H. C. H. Mulvad, M. Galili, H. Hu, T. Morioka, L. K. Oxenløwe \\ DTU Fotonik, Technical University of Denmark, Ørsteds Plads, 343, Kgs. Lyngby, 2800, Denmark \\ pengu@fotonik.dtu.dk
}

\begin{abstract}
We propose an all-optical ultra-high-speed OFDM to Nyquist-WDM conversion scheme based on complete OFT. An 8-subcarrier $640 \mathrm{Gbit} / \mathrm{s}$ DPSK OFDM super-channel is converted to eight $80-\mathrm{Gbit} / \mathrm{s}$ Nyquist-WDM channels with BER $<10^{-9}$ performance for all channels. OCIS codes: (060.4510) Optical communications; (060.4230) Multiplexing; (070.7145) Ultrafast processing.
\end{abstract}

\section{Introduction}

Due to the rapid traffic growth in optical communication networks, intensive efforts have been made to use the available bandwidth of optical fibers more efficiently. Recent studies have focused on orthogonal frequency division multiplexing (OFDM) and Nyquist wavelength division multiplexing (Nyquist-WDM), due to their high spectral efficiency (SE), which enable a channel spacing equal to the symbol rate. These multiplexing techniques have been used to demonstrate high SE super-channels with Tbit/s capacity [1-2]. The capability to switch between ultra-dense OFDM and Nyquist-WDM networks could become a very important functionality for the next generation communication systems. However, such functionality is presently not possible unless complex optical/electrical/optical conversion is used. Over the last ten years, time-domain optical Fourier transformations (OFT), also known as optical time lenses, have been shown to be a very versatile and powerful tool for ultrafast signal processing. It can be used for manipulating the shapes of optical signals in both the time- and frequencydomains. This has led to demonstrations of e.g. distortion-less transmission [3], optical time-division multiplexing (OTDM) to WDM conversion [4], all-optical OFDM transmission systems [5], and most recently WDM to NyquistOTDM conversion using a complete OFT [6].

In this paper, we propose an all-optical ultra-high speed OFDM to Nyquist-WDM conversion scheme based on complete OFT. Using this scheme, we simultaneously convert an 8-subcarrier $640 \mathrm{Gbit} / \mathrm{s}$ differential phase-shift keying (DPSK) OFDM super-channel to eight 80-Gbit/s Nyquist-WDM channels. The total signal bandwidth of $800 \mathrm{GHz}$ remains unchanged after conversion, thus maintaining the $\mathrm{SE}$ at $0.8 \mathrm{symbol} / \mathrm{s} / \mathrm{Hz}$. A full bit error rate (BER) characterization is performed, demonstrating BER $<10^{-9}$ performance for all converted channels. To the best of our knowledge, this is the first demonstration of OFDM to Nyquist-WDM conversion.

\section{Principle}

The OFDM signal is composed of sinc-shaped subcarrier spectra with rectangular waveforms. In contrast, the Nyquist-WDM signal is composed of WDM channels with rectangular spectra and sinc-shaped waveforms. Thus, the OFDM to Nyquist-WDM conversion can be realized by exchanging the temporal and spectral profiles, which can be done by a complete OFT [6]. The principle of the proposed scheme is shown in Fig. 1, including also an alloptical OFDM transmitter and a Nyquist-WDM receiver. In the all-optical OFDM transmitter, a multi-carrier transmitter generates a number of channels with frequency spacing $\Delta v_{1}$ at symbol rate $\mathrm{f}_{\mathrm{s}}(\mathbf{A})$, where $\Delta v_{1}$ is $\mathrm{N}$ times $\mathrm{f}_{\mathrm{s}}$. The multi-carrier channels with flat-top temporal waveforms are bit-wise synchronized. A rectangular temporal gate with width $\boldsymbol{T}_{\mathrm{ps}}=1 / \Delta v_{1}$ is then used to select the center of the overlapping waveforms, resulting in sinc-shaped multicarrier channels in the frequency-domain with a half zero-crossing width (HZCW) equal to $\Delta v_{1}(\mathbf{B})$. The signal is

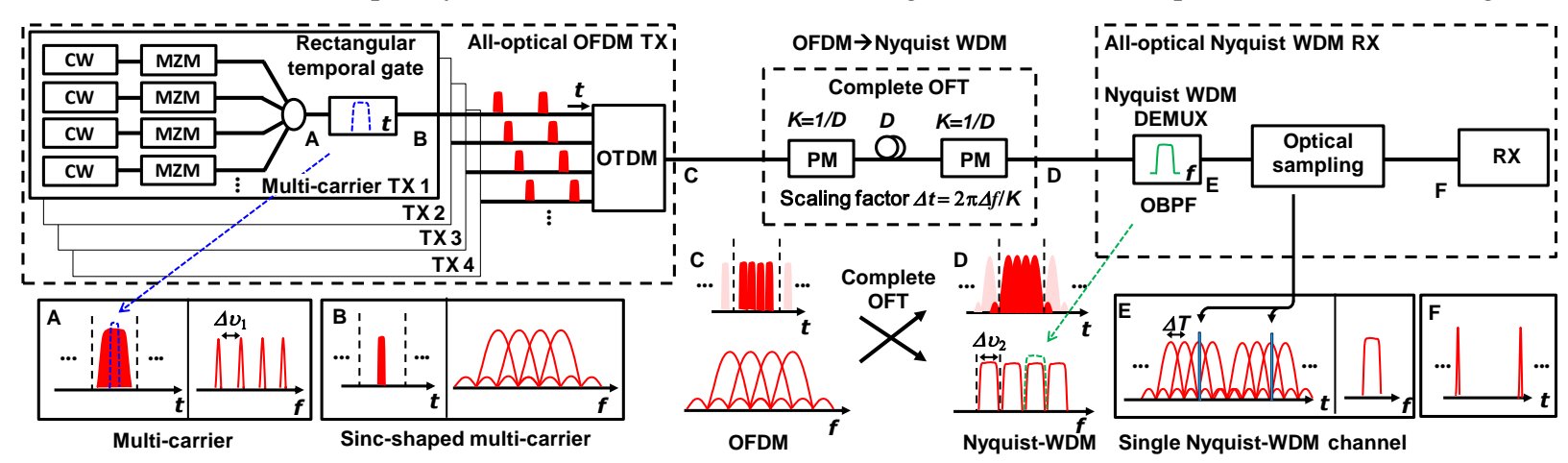

Fig. 1. The principle of all-optical ultra-high speed OFDM to Nyquist-WDM conversion. 


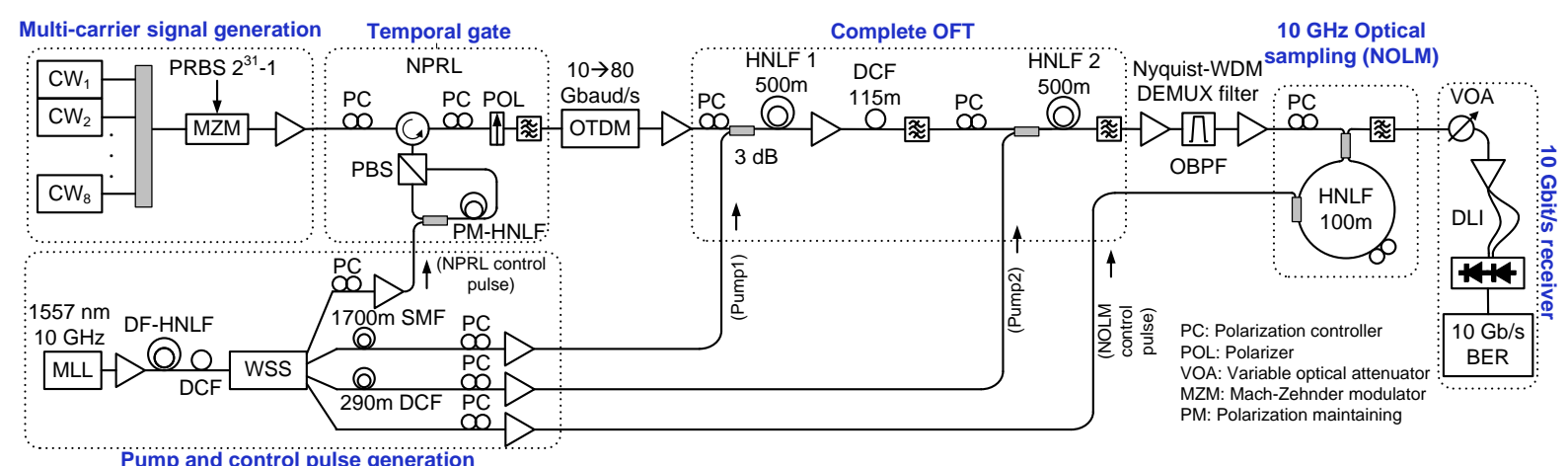

Fig. 2. Experimental setup for conversion of an 8 -subcarrier $640 \mathrm{Gbit} / \mathrm{s}$ OFDM super-channel to an $8 \times 80$-Gbit/s Nyquist-WDM channel. then OTDM-multiplexed by a factor $\mathrm{N}$, resulting in an OFDM signal with a symbol rate equal to the channel spacing (C), where $\mathrm{Nf}_{\mathrm{s}}=\Delta v_{1}$. The complete OFT for OFDM to Nyquist-WDM conversion is based on two quadratic phasemodulation stages (time lenses) with chirp rate $K$, separated by a dispersion medium of $D=\beta_{2} L$ (where $\beta_{2}$ is 2 nd order dispersion and $L$ is the length), which satisfy the condition $K=1 / D$ (a K-D-K configuration). This configuration enables both time-to-frequency and frequency-to-time conversions at the same time, thus performing an exchange between the temporal and spectral profiles of the input signal (a "complete" OFT). The chirp rate $K$ determines the scaling factor between the time and frequency domains according to $\Delta t=2 \pi \Delta f / K$. After the OFT, the OFDM signal is converted to a Nyquist-WDM signal with channel spacing $\Delta v_{2}$ depending on the choice of $K$ (D). To achieve the maximum SE after conversion, the chirp rate $K$ should be set equal to $2 \pi \Delta v_{1}{ }^{2}$. However, since the practical OFT process requires a short guard interval (GI) in each OFDM symbol slot for the transition of the quadratic phase-modulation, the $K$ is usually set to a value less than $2 \pi \Delta v_{1}{ }^{2}$. Note that the proposed scheme enables OFDM to Nyquist-WDM conversion at the super-channel level (not at the subcarrier-level), in the sense that an individual Nyquist-WDM channel is converted from the corresponding OFDM temporal tributary. In the receiver, the converted Nyquist-WDM super-channel is first WDM-demultiplexed into individual Nyquist-WDM channels (E) using a rectangular optical band-pass filter (OBPF) with bandwidth equal to the channel spacing $\Delta v_{2}$. The demultiplexed Nyquist-WDM channel is subsequently sampled at the inter-symbol-interference (ISI)-free point using a narrow optical sampling gate [7]. Finally, the sampled signal (F) is detected by a base-rate receiver. As the OFT is transparent to the data-format [8], this scheme could potentially be applied to advanced modulation formats.

\section{Experimental setup and results}

The experimental setup is shown in Fig. 2. Eight distributed feedback laser diodes (DFB-LDs), centered from $1547.2 \mathrm{~nm}$ to $1552.8 \mathrm{~nm}$ with $100 \mathrm{GHz}$ spacing, are used in the transmitter. The outputs of the CW lasers are DPSKmodulated with a $10 \mathrm{Gbit} / \mathrm{s} 2^{31}-1$ PRBS in a Mach-Zehnder modulator. A 10-ps rectangular temporal gate is used to simultaneously shape all multi-carrier channels into $100 \mathrm{GHz} \mathrm{HZCW}$ sinc-shaped multi-carrier channels. The temporal gate is implemented by a non-linear polarization-rotating loop (NPRL) [9] using a 10-ps rectangular control pulse. The obtained eight 10-Gbaud sinc-shaped multi-carrier channels are then OTDM-multiplexed to 80Gbaud using an OTDM multiplexer, resulting in an 8-subcarrier 640 Gbit/s OFDM super-channel with SE at 0.8 symbol/s/Hz, as shown in Fig. 3 (a). Fig. 3 (a) also shows the 8 OFDM subcarriers with $100 \mathrm{GHz}$ spacing obtained from the individual CW lasers, where the characteristic sinc-shape can be observed. The resulting OFDM waveform is shown in Fig. 3(b), where the 80-Gbaud rectangular-shaped OFDM waveform is obtained. The bit slot is 11.5 ps including a 1.5-ps GI, and an extra 8-ps GI between every 8 tributaries for OFT operation.

A complete OFT is used for the OFDM to Nyquist-WDM conversion. The quadratic phase modulation is implemented based on a four-wave mixing (FWM) process in a highly nonlinear fiber (HNLF) using linearly
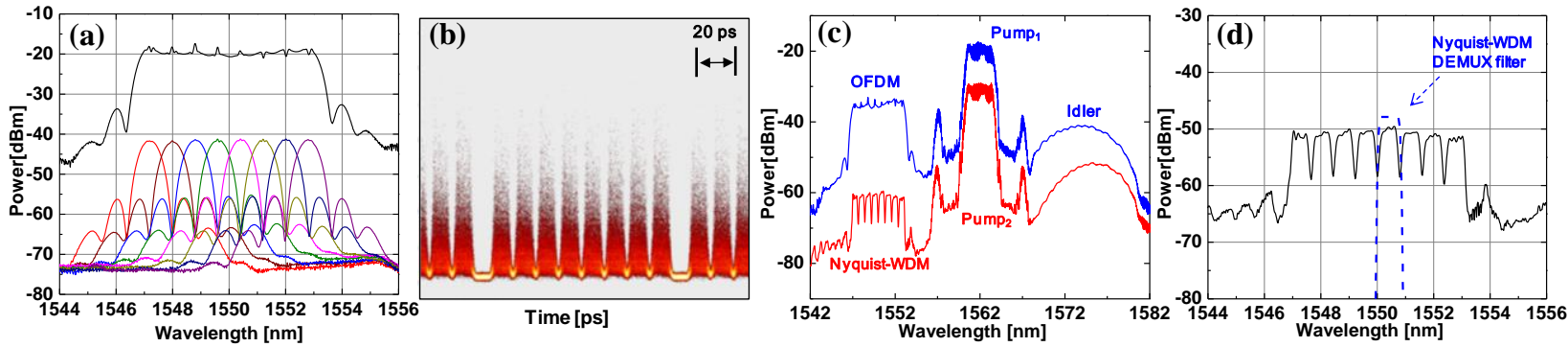

Fig. 3. Results of OFDM to Nyquist-WDM conversion, (a) obtained OFDM spectrum and sinc-shaped subcarriers from individual CW lasers, (b) obtained OFDM waveform, (c) optical spectrum after the first (blue) and second (red) FWM process, (d) obtained Nyquist-WDM spectrum 

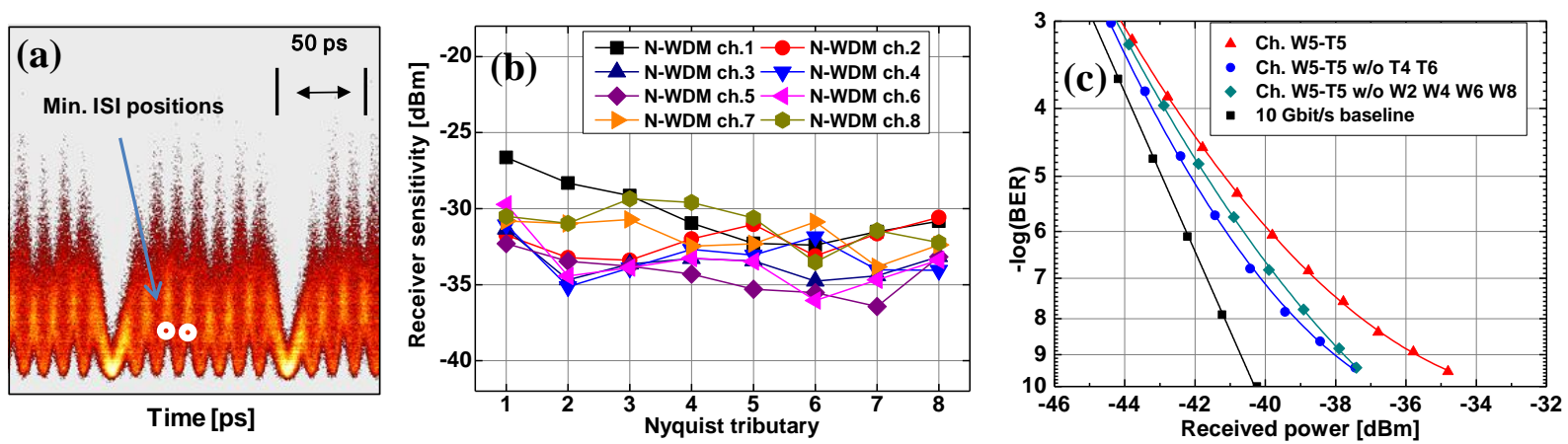

Fig. 4 Experimental results, (a) waveform of WDM-demultiplexed Nyquist-WDM channel 5, (b) receiver sensitivities at BER=10 $0^{-9}$ of all converted Nyquist-WDM channels, (c) BER performance of the best converted $10 \mathrm{Gbit} / \mathrm{s}$ DPSK Nyquist tributaries

chirped rectangular pump pulses. The pump pulses are obtained from a $10 \mathrm{GHz}$ MLL at $1557 \mathrm{~nm}$ followed by spectral broadening in a dispersion-flattened HNLF (DF-HNLF). To obtain linearly chirped pumps, the output spectrum of the DF-HNLF is filtered using a wavelength selective switch (WSS), and each pump is subsequently propagated in an appropriate length of dispersive fiber. Pump $p_{1}$ is dispersed in $1700 \mathrm{~m}$ of SMF to achieve a chirp rate $K=0.055 \mathrm{ps}^{-2}$ for conversion of the $11.5 \mathrm{ps}$ temporal spacing to a $100 \mathrm{GHz}$ frequency grid $\left(K<2 \pi \Delta v_{1}^{2}\right.$ due to the insertion of a GI). As the data-signal is phase-conjugated after the first FWM process, pump 2 is dispersed in $290 \mathrm{~m}$ of dispersion compensating fiber (DCF) having the opposite dispersion value of the $1700 \mathrm{~m} \mathrm{SMF}$, in order to achieve the same chirp rate $K$. The central wavelengths of the pumps are set at $1562 \mathrm{~nm}$. The first FWM output is shown in Fig. 3 (c). After extraction with a $14 \mathrm{~nm}$ OBPF, the idler is dispersed in $115 \mathrm{~m}$ DCF, then combined with pump $_{2}$ and coupled into $\mathrm{HNLF}_{2}$ for the second FWM process. The resulting spectrum is also shown in Fig. 3(c). The generated idler is the Nyquist-WDM super-channel converted from the OFDM signal. Fig. 3 (d) shows a zoom-in on the idler, where 8 rectangular Nyquist-WDM channels with $100 \mathrm{GHz}$ spacing can be observed, and the SE remains at $0.8 \mathrm{symbol} / \mathrm{s} / \mathrm{Hz}$ after conversion.

In the receiver, a $100 \mathrm{GHz}$ rectangular OBPF is used to demultiplex each Nyquist-WDM channel as shown in Fig. 3 (d). Each 80-Gbit/s Nyquist-WDM channel contains eight 10-Gbit/s Nyquist tributaries. Fig. 4 (a) shows the waveform of a WDM-demultiplexed 80-Gbit/s Nyquist-WDM channel, where 8 minimum-ISI positions with 11.5-ps spacing are clearly observed. These minimum-ISI positions correspond to the nulls of the sinc-shaped tributary waveforms. The minimum-ISI position in each 11.5-ps tributary time-slot is then sampled in the NOLM, using a 1.3-ps wide control pulse for gating. Finally, the BER of each tributary is measured in a 10-Gbit/s preamplified DPSK receiver including a delay line interferometer (DLI) and a balanced photo-detector.

Fig. 4 (b) shows the receiver sensitivities at $B E R=10^{-9}$, which is achieved for all $6410-\mathrm{Gbit} / \mathrm{s}$ DPSK tributaries within the 8 converted Nyquist-WDM channels. As a BER curve example, one of the best Nyquist tributaries (W5T5: tributary 5 from Nyquist-WDM channel 5) is plotted in Fig. 4 (c). BER $<10^{-9}$ is achieved with a receiver sensitivity of $-35.7 \mathrm{dBm}$. For reference, the BER curves of the same tributary without adjacent tributaries and neighboring Nyquist-WDM channels are also shown in Fig. 4 (c) respectively, as well as a $10 \mathrm{Gbit} / \mathrm{s}$ DPSK baseline. The power penalty for the best tributary is $5 \mathrm{~dB}$ for the full system (including all-optical OFDM generation, OFDM to Nyquist-WDM conversion and optical sampling), of which $2.3 \mathrm{~dB}$ is due to the ISI from the adjacent tributaries and $2 \mathrm{~dB}$ is due to the neighboring Nyquist-WDM channels.

\section{Conclusion}

We have proposed a novel all-optical ultra-high-speed OFDM to Nyquist-WDM conversion scheme based on complete OFT. An 8-subcarrier $640 \mathrm{Gbit} / \mathrm{s}$ DPSK OFDM signal was simultaneously converted to eight $80-\mathrm{Gbit} / \mathrm{s}$ Nyquist-WDM channels, achieving BER $<10^{-9}$ performance. The SE remains unchanged at $0.8 \mathrm{symbol} / \mathrm{s} / \mathrm{Hz}$ after conversion, which is close to the binary single channel theoretical limit of $1 \mathrm{symbol} / \mathrm{s} / \mathrm{Hz}$. In principle, this OFTbased technique can also be employed for Nyquist-WDM to OFDM conversion, and it could therefore provide a simple and energy-efficient link between spectrally efficient OFDM and Nyquist-WDM systems.

Acknowledgements: OFS Denmark Aps, Danish Research Council FTP project TOR (ref. no. 12-127224).

\section{References}

[1] D. Hillerkuss et al., Nature Photonics 5(6), 364-371 (2011).

[2] J. Schröder et al., J. Lightwave Technol. 32(4), 752-759 (2014).

[3] M. Nakazawa et al., IEEE PTL. 16, 1059-1061 (2004).

[4] H. C. H. Mulvad et al., Proc. OFC 2011, OThN.2 (2011).

[5] P. Guan et al., Proc. OFC 2014, W4F.1 (2014).
[6] P. Guan et al., Proc. ECOC 2014, We.2.5.5 (2014).

[7] M. Nakazawa et al., Opt. Express, 20(2), 1129-1140 (2012).

[8] E. Palushani et al., Proc. OFC 2012, OTH3H.2 (2012).

[9] H. C. H. Mulvad et al. Proc. ECOC 2008, Tu.3.D.6 (2008). 